\title{
Co-designing the next generation of home energy management systems with lead-users
}

Andrew D. Peacock, , Joel Chaney ${ }^{\mathrm{a}}$, Kristin Goldbach ${ }^{\mathrm{b}}$, Guy Walker ${ }^{\mathrm{a}}$, Paul Tuohyc, Salvador Santonja ${ }^{d}$, David Todolid ${ }^{d}$ Edward H. Owens ${ }^{a}$

Heriot-Watt University ${ }^{a}$, Fraunhofer Institute for Solar Energy Systems ISE ${ }^{\mathrm{b}}$, University of Strathclyde ${ }^{c}$, Instituto Tecnológico de Informática ${ }^{d}$ 


\begin{abstract}
Home energy management systems are widely promoted as essential components of future low carbon economies. It is argued in this paper that assumptions surrounding their deployment, and the methods used to design them, emerge from discredited models of people and energy. This offers an explanation for why their field trial performance is so inconsistent. A first of a kind field trial is reported. Three eco communities took part in a comprehensive participatory design exercise as lead users. The challenge was to help users synchronise their energy use behaviours with the availability of locally generated renewable energy sources. To meet this aim, a set of highly novel Home Energy Management interfaces were co-designed and tested. Not only were the designs radically different to the norm, but they also yielded sustained user engagement over a six-month follow-up period. It is argued that user-centred design holds the key to unlocking the energy saving potential of new domestic technologies, and this study represents a bold step in that direction.
\end{abstract}

Keywords: Participatory design, home energy management systems, renewable generation, energy use behaviour 


\section{INTRODUCTION}

\subsection{Background and Context}

Reducing greenhouse gas emissions is a defining global issue. It is becoming increasingly apparent that targeted reductions will only be met if behavioural factors associated with energy use are better understood. The EU has set ambitious goals for reducing its greenhouse gas emissions, with reductions of between $80-95 \%$ by 2050 targeted (EU, 2011). This is mirrored by policy initiatives in most member states. The UK Government, for example, has legislated for a reduction of no less than $80 \%$ by 2050 in its 2008 Climate Change Bill (DECC, 2015a). Scenario analysis has been conducted to explore the major technical, social and economic changes required to meet these targets and one transition consistently emphasised is the human factor (UK ERC, 2013; Foxon, 2013). The issue cannot be understated: for these emissions targets to be met, it is imperative that residential energy consumers play a more active role in the operation of the energy network. This is very likely to occur through greater acceptance of smart technology whereby appliances and heating systems are remotely controlled to benefit energy network management. In tandem, householders will be actively encouraged to change their pattern of energy use,facilitated by improved quality and relevance of information regarding their energy consumption and through the introduction of incentivised tariff schemes (Peacock and Owens, 2013). New methods of communicating to households about how they are interacting with the surrounding energy network will have to emerge.

The Orchestration of Renewable Integrated Generation in Neighbourhoods (ORIGIN) project, of which this research forms a part, explored how the increasingly active role required of the householder might become manifest. This role includes actuated, informational and incentivised methods of modifying patterns of consumption. The project is highly novel in that it involves three eco-communities; the Findhorn Foundation in Northern Scotland, the Damanhur Community in Northern Italy and the Tamera Bio-sphere in Southern Portugal. These communities represent a sample of highly engaged energy users whose insights could help drive out user-centred design solutions for all. This paper describes the process and outcomes of a participatory design process that sought to understand how information should be devised and communicated to individuals in those communities in order to encourage greater proportions of energy to be consumed from locally deployed renewable generation systems. The effectiveness of the developed informational systems was then assessed by examining the user experience coupled with usage statistics in each community. 


\subsection{Communicating Information about Energy Use to Households}

Information on energy usage, for the majority of domestic consumers, is invisible on three levels:

i. The method of delivering energy to the home is invisible. It arrives unseen through wires and pipes which themselves are concealed in the building fabric. Consumers do not see the actual energy, or indeed the consequences of its consumption, just the indirect outputs some of which are counterintuitive. For example, some low power devices will consume more energy because they are left on all the time, or require some form of information infrastructure (like the internet or the cloud) which also consume power.

ii. The services to which energy consumption is directed are often habitual in nature, rooted in unquestioned social practices and routines (Strengers, 2011; GramHanssen, 2008; Shove 2007). These include matters such as cleanliness and conventions around clothes or dishwashing, for example. Social practices such as these make it difficult for consumers to establish linkages between their (unquestioned) activity and their actual consumption.

iii. Finally, over half of UK dwellings purchase their electricity via an automated monthly transaction between the householder's bank and their electricity retailer (DECC, 2015b). This further removes the direct link between behaviours and consumption.

As a result of these three features, householders can be unaware that a commodity has been delivered; unaware that they have used it; and unaware that they have purchased it. Home energy monitoring (HEM) systems have been promoted over the last two decades in part to overcome these invisibility issues. In policy terms HEM systems are seen as a key enabler in the transition towards active electricity consumers (Stern, 2007). Under the provisions of the EU Third Energy Package, member states are required to prepare a timescale for the deployment of intelligent metering systems, comprising some form of HEM implementation (European Commission, 2014). In the UK, for instance, intelligent metering will be fitted to all dwellings by 2020 (a process underway at the time of writing) and their deployment is anticipated to result in a $8.1 \mathrm{TWh}(1.8 \%)$ reduction in total household energy consumption (DECC, 2014). While a certain common-sense engineering logic is understandable - after all, if consumers are given explicit information why wouldn't they change their behaviour? - the evidence-base is far more uncertain. A wide range of studies have examined the efficacy of providing energy feedback and other information to consumers and the resulting changes in their behaviour. Some of these have been extremely ambitious and large-scale in nature. Faruqui et al. (2010), for example, reports on 
12 energy feedback trials of varying duration, motivation, participant demographics, hardware and software configuration, conducted in the US by utility companies over the space of 22 years from 1989 to 2011 . The average savings reported by each program ranged from $0 \%$ to $18 \%$. This is far more modest than is often anticipated. Equally ambitious studies such as Darby (2006), Fischer (2008), and the work of Ehrhardt-Martinez et al. (2010) which reviewed pilot trials going back as far as 1977, reveal mixed findings. Energy savings were found to range from $0 \%$ (i.e. zero change in energy-use behaviour despite the often substantial investment in HEM technology) to a maximum of $32 \%$. This level of uncertainty from controlled field trials is indicative of an unstable technology and a sociotechnical system which is not yet fully understood. This becomes even more manifest when the longitudinal effects are examined (Faruqui, 2010). The majority of trials only monitor householder responses for relatively short periods of time (less than 4 months). In a 15 month pilot trial in the Netherlands approximately $40 \%$ of participants were no longer interacting with their HEMS at the conclusion of the study (van Dam et al., 2010). A UK trial found that consumer engagement could be extended by developing interactive usage strategies, such as the weekly input of data from the gas meter (Burchell, 2014). Despite this $30 \%$ of users had disengaged after 12 months. Not unsurprisingly, participants who had become disengaged provided negative feedback for the displays they had been provided (Darby, 2006). Research consistently shows that HEMS displays are not well designed (e.g. Walker et al., Under Review; Wallenborn, 2011) and that users are frequently excluded from the design process. Karjalainen (2010) stresses the point that a "one-size fits all" strategy cannot be justified in the selection of HEMS design concepts, a point reinforced by Hargreaves et al. (2010) who observed that a participant's style of engagement with HEMS was gender and age specific. In a Norwegian study, differences between various types of households in their interactions with in-home displays were detected based on their level of affluence and their previous interaction with household energy data (Westskog et al., 2015). Fischer (2008) and Stromback et al. (2011) both identify a wide range of other HEM characteristics that play a role in their effectiveness. The challenges, then, are both significant and clear. Common to the majority of these previous HEMS studies is an underlying theory or model of human behaviour that this paper seeks to explore more fully.

\subsection{The Information Deficit Model}

Why is there a sometimes significant gap between what should be common sense and the practical realities of domestic energy consumption? Why do domestic energy users not behave in ways that engineering logic would suggest is rational? The answer appears to lie 
in the assumptions contained in the Information-Deficit Model (IDM: Hargreaves 2010). This assumes that the householder, once in receipt of the 'correct information', will make rational, economic decisions about energy consumption based on their individual attitudes and beliefs. Despite this model running counter to over forty years of research in decision making and cognitive biases (e.g. Kahneman, 2011), and the model itself widely debunked (e.g. Strengers, 2011; Hargreaves, 2010; Gram-Hanssen, 2011), most HEMS research still relies on the assumption that if the 'correct' information is 'made visible' then users will respond in ways that are predictable and desirable. In order to advance the research agenda a stronger focus on user-centred design is required but the challenges involved in doing this are themselves significant (Pruitt \& Adlin, 2010). A conventional and widespread approach to gaining an understanding of users is by collecting quantitative and qualitative data using a range of methodologies that may include surveys, focus groups, and semistructured interviews. A recurring issue for energy researchers is that the HEMS designer (often expert in electrical engineering) may not have the skill set necessary (social sciences) to collect and interpret data in this manner, and therefore will receive information that has been translated by a third party, immediately placing a distance between the user and the designer. Burr and Matthews (2008) put forward three approaches that can be used to overcome this difficulty and create a framework within which users can be engaged in the co-innovation of products and services.

The first is the Lead User Approach. This describes a user group who experience future market needs months or years ahead of the bulk of the market. Clearly identifying these 'right' users is critical to success and Tognazzini (1995) raises the issue that designers quite often seek out users who are like themselves to provide feedback. The second approach is Design Anthropology which requires the designer to work and/or live for extended periods of time with the people for whom the product or service is being designed. Whilst this approach may provide the most comprehensive understanding of users and context of use, a number of practical difficulties can be encountered, not least rationalising its (often long) timescales with those of a typical design process. The third approach is Participatory Design, which describes a suite of approaches that purposely recasts the role of the designer and the user as co-creators (e.g. Ehn, 2008). All of these approaches, to some degree, describe the creation of systems by a process that starts by agreeing a shared object of concern. This is followed by a participatory design phase where a device is created that addresses this object of concern. There is then a meta-design phase where the device in the hands of the user becomes a thing or a proliferation of things. Participatory design answers some significant concerns with the Information Deficit Model, but it is not without concerns of its own. Principle among these is the potential disconnect between the outputs 
of the participatory design process and the actual performance of the device that has been designed.

\section{THE CURRENT STUDY}

\subsection{Objectives}

In this paper a new and highly innovative HEMS is subject to development but in a way that blends these three approaches and addresses critical shortcomings therein. A lead-user group formed of three eco-communities is employed. This group not only has a high level of energy awareness but they also have long experience in the deployment of certain technologies (like local renewable energy) that are becoming increasingly commonplace. The communities were engaged with by the multi-disciplinary research team over a period of three years consistent with design anthropology approaches. Stemming from this is a large scale participatory design exercise where the object of concern is an interface to allow users to synchronise their energy use with the availability of locally generated renewable energy sources. The outputs of this exercise form the topic of Sections $2 \& 3$. Section 4 then proceeds to test user experiences with the HEMS within the eco-communities in question. Between them the studies represent a ground-breaking approach to the design of HEMS and a direct challenge to the information deficit model. It is argued that these and similar comprehensive user-centred approaches, and the varied theories and methods to be found in the human factors sphere, are not represented strongly enough in the wider energy-use literature. The wider aim of this paper is to reveal the insights available when user-centred approaches like these are put to use.

\subsection{Participants}

The participants in this study were users who lived in three intentional eco-communities, Findhorn in Northern Scotland, Damanhur Community in Northern Italy, and the Tamera Biosphere in Southern Portugal. Eco-communities of this type can be defined as "human scale full-featured settlements in which human activities are harmlessly integrated into the natural world in a way that is supportive of healthy human development and can be successfully continued into the indefinite future" (Gilman, 1991). Participants were not only aware of environmental issues but were actively seeking to live more sustainably. This aspiration was in part met by local renewable energy generation. The participation of these lead users on the "extreme" of environmental awareness is useful to unearth unarticulated behaviours, desires and needs that may be (or become in future) relevant to the rest of the population (IDEO, 2011). Conceptually, the use of three communities from different countries could potentially have introduced interesting international/cultural aspects to the study. However, community engagement was found to be determined less by their geographical location per 
se than the objective function each pursued. This was determined in part by their method of community collectivisation and by techno-economic aspects of the energy systems operating in each community.

A lead-user advisory group was created in each community with the members attending the participatory design workshop. The scope of the lead user advisory group together with the details of the workshop (e.g. date, timing, location and agenda) was circulated to each community four weeks prior. Membership of the lead-user advisory group was voluntary and was drawn from community members who had been exposed to the ORIGIN project throughout its duration (18 months at the time of the workshop) and were already conversant with its aims and objectives. In addition to information demand response programmes, the ORIGIN project also evaluated tariff-based programmes within the Findhorn Community. The Findhorn workshops were therefore dominated by design and communication of these tariff-based programmes and described in companion papers (see for instance ORIGIN, 2015). In the Damanhur Community there were nine participants, four female and five male, ranging in age from 34 to 62 years. In Tamera there were seven participants of whom five were male and two were female, ranging in age from 32 to 54 years.

Participants gave their formal consent to participate in the study and did so voluntarily without payment. Participants could withdraw from the study without penalty and were fully briefed on the study aims and objectives. Formal ethical approval was granted by the Ethics Committee of Heriot-Watt University's School of Energy, Geoscience, Infrastructure and Society.

The research group attending the workshops numbered four and contained energy analysts, computer scientists and graphical designers who together had the responsibility for creating the physical artefacts that would constitute the eventual ORIGIN HEMS. Their role was informed by the approach taken by Ehn (2008) who described the designer's knowledge in a participatory process as being associated with the conception and implementation of "design devices" (prototypes, mock-ups, games, models and sketches).

\section{PARTICIPATORY DESIGN WORKSHOPS}

\subsection{Materials and Procedure}

A participatory design approach was adopted based on research principles described by Martin and Hannigton (2012). Their approach was modified to ensure it did not merely constitute a design methodology that involved the users but rather a process that cast users and the research group as co-creators. Aiding this was a high degree of design anthropology, with the research team embedded in and constantly engaging with the communities in the 18 months prior to this study taking place. The design of the workshop is 
represented in Figure 1. The initial phase was a participatory design workshop with the aim to produce design input for the HEMS.

Figure 1 goes about here

\subsection{Methodology}

The procedure followed by the participatory design exercise (Phase 1 in Figure 1) involved six steps which are described in detail below. The workshops were audio recorded and transcribed in support of the subsequent analysis.

Step 1: Define Object of Concern

The research group were responsible for defining the object of concern. This was presented to the participants at the start of the workshop. Two objects of concern were defined and described as:

Object of concern 1: Communicating renewable generation availability

How would you like to be told about there being a surplus of renewable generation in your community?

How would you like to be told about there being a surplus of renewable generation in your household?

Object of concern 2: Communicating performance feedback

How do you know what the impact of your response has been?

How do you want to get feedback on how you are doing?

The participants were able to question the research group to clarify any issues associated with the two objects of concern to ensure that meaning and understanding were clear. The workshop was split into two sections, one for each object of concern. The methodology described below was applied in each case. Each step in the process is illustrated predominantly using examples of output from the section that dealt with the first object of concern, but apply equally to both.

The participants were free to organise themselves as they chose. In Damanhur, the participants arranged themselves in three groups but in Tamera only one larger group was formed. The research team embedded itself into these groups. 
Step 2: Community discuss solutions

Each group was asked to discuss and debate ways in which the object of concern might be addressed. The community participants were provided with no additional information other than the questions that described the object of concern. They were requested to develop a minimum of four approaches. At the conclusion of the session one member from each group presented their concepts to the other participants and to the research group.

\section{Step 3: Introduce existing solutions}

Prior to the workshop, the research group identified a number of existing methods that are or have been used to address the objects of concern. The designers purposely selected a variety of methods to encourage a breadth of discussion. For instance, they included physical objects that communicated instantaneous availability of energy, such as the Ambient Orb (Ambient Devices, 2014) and digital displays that forecasted availability (colour coded clock face). The research group produced posters containing pictorial and written descriptions of these existing methods but applied to their specific object of concern. These posters were all pinned to one wall of the workshop room which was dubbed 'the wall of ideas.' The research group presented details about each market solution to the participants that included where and when it had been applied. The participants were able to question the research group to ensure the description of each existing method of information display was clear.

\section{Step 4: Community create solutions}

The participants were then asked to develop a series of new concepts. These could be based on their own concepts from Step 2, the existing methods from Step 3, a crossfertilisation of the two, or completely new concepts they had developed that the process to date may have inspired. Participants were asked to produce posters for each design concept that included an image and a description that explained how it would address the research agenda.

Step 5: Display community \& existing solutions

Participants then presented their design concepts to all participants and to the research group and added their posters to 'the wall of ideas.'

Step 6: Community select best solutions 
The participants were then asked to consider all the concepts, both those generated during the workshop and the market solutions. Participants then voted to either like, dislike or ignore each concept by marking the poster with a green cross, a red cross or no cross respectively. The ideas that were either wholly disliked or ignored were separated from the liked concepts and a second round of voting carried out where participants were asked to vote for their favourite approach and second favourite approach, these receiving two and one points respectively. Those ideas receiving the highest share of the vote were then used as primary input by the research group in the creation of the initial ORIGIN HEMS, which was then put forward for more formal testing and evaluation.

\subsection{Results from Participatory Workshops}

\subsubsection{Community Solutions}

A wide range of ideas and solutions were generated by the participatory design workshop participants. Those that were developed furthest and picked up on the central themes emerging from the discussions are show in Figure 2. A number of interesting insights were gained. Visual means were preferred for communicating the availability of hot water generated using solar thermal systems. These included lights or a flag above the shower blocks that could be seen from a distance (Figure 2a), and forecast clocks either physically located in communal areas or hosted by phone apps (Figure 2b). If data were to be used to express availability of hot water it would be expressed in contextual units (e.g. number of showers) rather than abstract units (e.g. kWh of hot water left in a thermal store). Similarly, imagery was preferred for indicating the availability of electricity generated by building integrated Solar-PV systems, e.g. a flower that would bloom when low carbon electricity was available (Figure 2c). A running horse whose pace would be a function of the availability of locally generated renewable electricity (Figure $2 \mathrm{~d}$ ) was also designed by the lead user group. All of these ideas go considerably beyond the information deficit model, and evidence a range of creative ideas designed to blend into domestic life as lived in these settings.

Figure 2 goes about here 


\subsubsection{Ranking and Prioritisation}

The contribution of the participants in the workshop at each site varied quite considerably. At the conclusion of the exercise there were four community-led design concepts put forward at Tamera (Figure 3), and ten at Damanhur (described in and Figure 4). When all the concepts were ranked by all the participants, it was clear that the Tamera community tended to place a premium on visual imagery to display availability of renewable generation, with the most popular concept being a physical object rather than one that could only be displayed on a digital medium. Likewise, in Damanhur, the most popular concept was a graphical representation of renewable generation availability. In both communities, the most popular HEMS concepts described information at a community rather than individual or household level. Overall, community led design ideas received $71 \%$ and $63 \%$ of the 'liked votes' in Tamera and Damanhur respectively.

Figure 3 goes about here

Figure 4 goes about here

\subsubsection{Final Co-Created HEMS Design}

The design output from Step 6 of the participatory design process identified a preference for a mixture of ways in which the objects of concern should be addressed. These included numerical and visual digital displays and physical objects, e.g. in the form of lighting systems or clocks. Initial prototyping involved realising the co-created designs in a web based user interface consisting of a series of 'gadgets'. It was configured to be viewed on a computer and a smart phone, accessed through a unique user login and password provided to each participating household and building in each community. In all, thirteen unique gadgets were developed based on the workshop output (Figure 5). Ten gadgets addressed Object of Concern 1 and are named forecast gadgets, i.e. provided a forecast of renewable generation surplus; and three addressed Object of Concern 2 and are labelled feedback gadgets, i.e. gave feedback about how the community, household or building had responded to the forecasted surplus. Participants were able to customise their interface by selecting from the thirteen available gadgets, up to six of which could be viewed at any time. The web-based method enabled prototypes to be generated rapidly, and in a way that granted good flexibility around the key issues of content, location and timing of information.

Figure 5 goes about here 


\section{EVALUATING THE CO-CREATED DESIGN}

\subsection{Assessment period}

The initial design was then deployed and a formal evaluation phase initiated where users could provide feedback, assess its suitability and suggest improvements. This phase was carried out after the HEMS had been deployed and had been in use for six months. In addition, the individual interaction of users in each community with the HEMS was logged over an eight month period (16th March 2015 to 21st October 2015).

\subsection{ORIGIN HEMS Usage Patterns}

\subsubsection{Methodlogy}

The results now turn to how the co-designed ORIGIN HEMS system was actually used in practice. The ORIGIN project itself took place over three years between 2012 and 2015. During the first year each community were canvassed by community members to enlist their involvement. A total of 172 individual users were registered and had access to the codesigned ORIGIN HEMS system, split into $n=30,68$ and 74 users in Tamera, Damanhur and Findhorn respectively. Each community was then audited and monitoring and actuating systems designed, procured and installed in the participating building and energy systems. In the second year, energy supply and consumption was monitored to create a baseline of energy-use performance. The monitoring phase allowed this baseline to be quantified, normalised, and adjusted for different energy supply and demand characteristics such as wind speed, cloud cover, time of day, time of year.

In the third year an array of mechanisms were deployed that were designed to achieve the wider aims of the ORIGIN project. These included actuated load shifting of heating systems, a rebate based electricity tariff linked to instances of surplus renewable generation, and the topic of this paper, the co-designed ORIGIN HEMS system. Interaction with the ORIGIN HEMS system by community participants was assessed by tracking log-in incidences and behaviours using individual user names.

The usage statistics were collated for the period 16th March 2015 to $21^{\text {st }}$ October 2015 . Up until the $17^{\text {th }}$ June 2015 only community level information was available in the ORIGIN HEMS, after which it was possible to access building level information. The usage statistics include the user name (unique for each user), the time at which the ORIGIN HEMS was accessed, the length of time it was live as a web page, the gadgets that were included and which (if any) gadgets had been removed or selected by the user during the session. 
Members of the lead user group who created the design input for the ORIGIN HEMS were included in the usage statistics.

\subsubsection{Results - User access}

In Tamera, 24 individual users out of a total of 30 registered participants (80\%) viewed the $\mathrm{UI}$ at least once (Table 1). Almost half of total interaction with the UI (420 of the 952 instances) was made by the Tamera technical team (four users). The technical team were community members, participants in the ORIGIN project and were responsible for managing the community energy assets. This relatively high percentage is to be expected as one of the primary aims of ORIGIN was for the technical team to find alternative control strategies for managing their electricity infrastructure. Of the three communities, the number of participants accessing the UI was lowest in Damanhur (Table 1). Only 20 unique users accessed the $\mathrm{UI}$ during the monitoring period out of a total of 68 registered individuals. This perhaps reflects the nature of the Damanhurian communities who may be viewing the $\mathrm{UI}$ as a collective rather than individual pursuit. Findhorn had the highest number of unique active users, constituting $62 \%$ of all registered users (Table 1 ). This is likely to be reflective of two distinctive features of the Findhorn field trial; (a) the number of unique users is equivalent to the number of participating households or buildings both of which are significantly higher than were included in the other two communities, and (b) the field trial included a rebate tariff scheme which incentivised participation in the demand response initiatives. In Findhorn, forecasted rebate periods were communicated to participants using a dedicated gadget on the ORIGIN HEMS.

Table 1 - User interaction with the co-designed HEMS system by residents in three ecocommunities over a six month period

\begin{tabular}{|l|l|l|l|l|}
\hline Community & $\begin{array}{c}\text { Number of } \\
\text { unique users }\end{array}$ & $\begin{array}{c}\text { Number of } \\
\text { Users who } \\
\text { accessed } \\
\text { ORIGIM HEMS }\end{array}$ & $\begin{array}{c}\text { Total number of } \\
\text { times ORIGIN } \\
\text { HEMS was } \\
\text { accessed }\end{array}$ & $\begin{array}{c}\text { Average access } \\
\text { /user }\end{array}$ \\
\hline Tamera & 30 & 24 & 952 & 40 \\
\hline Damanhur & 68 & 20 & 362 & 18 \\
\hline Findhorn & 74 & 46 & 5654 & 123 \\
\hline
\end{tabular}

\subsubsection{Results - Longevity}

The pattern of usage changed over the six-month study period. The mean number of HEMS interactions in Tamera increased from mid-March through to mid-July four fold, indicating an 
increasing interest in the $\mathrm{UI}$ with more unique users logging on (Figure 6). The mean number of monthly users reached a peak in July of 187 accesses per month falling back to 131 in August. Interestingly this fall off corresponds with the availability of another ORIGIN interface, the 'community screen' in the Campus kitchen. As residents regularly eat in this area they may be viewing the data via this screen rather than logging on individually.

In Damanhur, the average monthly number of users increased from mid-March through to mid-June again by four fold. This too indicates a growing awareness of the project with more unique users logging on (Figure 6). However, this increase was reversed from midJune to mid-August, with the number of users dropping markedly. This coincided with the designated ORIGIN champion leaving the community in July creating a vacuum of community representation. Community led initiatives can be fragile as by necessity initial project knowledge is concentrated among a few individuals. Encouragingly, the average monthly users increased again in September coinciding with the identification of a new champion. It tailed off slightly in October corresponding with the deployment of the community screen, a phenomena seen in the other communities.

In Findhorn, access peaked in mid-July (Figure 6). Of the 46 unique users, 14 individual users looked at the interface more than 100 times (more than three viewings per week) between March and October. It is likely that this was augmented by community screen viewings.

Figure 6 goes about here

\subsection{User Experience}

\subsubsection{Methodology}

Evaluating the user-experience of the ORIGIN HEMS was measured using the Attrakdiff2 model (Burmester, Hassenzahl, \& Koller, 2002) which collects and assesses data based on individual responses of system users to a questionnaire. The pragmatic (easy, complicated, controllable) and hedonic (valuable, novel, interesting, special) qualities of the software/dashboard were evaluated. It was found that both quality perceptions are independent from each other (Hassenzahl et al. 2008) and that taken together provide an overall assessment of attractiveness. This approach permitted the technological consequences of using the ORIGIN HEMS to be assessed from both a behavioural (i.e. the 
intensity and frequency of use: see above) and an emotional (i.e. the feelings of joy when interacting with the UI) perspective.

The analysis investigated the level of satisfaction of users, effectively measuring the extent to which the intended objectives defined by the participatory design process have been realised. The cognitive assessment of the quality and attractiveness partitions output from the assessment model into behavioural consequences and emotional consequences. Behavioural consequences relate to the intensity and frequency of use and the emotional level relates the feelings of joy when interacting with the $\mathrm{UI}$.

Measures

The questionnaire consisted of 28 different single bipolar items, with a seven point scale that was used as a semantic differential to measure the connotative meaning of the technology. An example question is:

"With the help of the word-pairs please enter what you consider the most appropriate description for the ORIGIN dashboard: human $\square \square \square \square \square \square \square$ technical".

This gives an example of one bipolar item, which was followed by the remaining 27 (e.g. isolating - connective, pleasant - unpleasant). Overall, the survey took approximately five minutes to complete.

Sample

Out of the estimated total of 150 residential users of the ORIGIN HEMS across all three communities, 54 participants have taken part in the survey, leading to an acceptable response rate of $36 \%$. Respondents encompassed 24 community members from Findhorn, 11 from Tamera and 19 from Damanhur. The average age of respondents was 55 years (ranging from 11 to 88 years). There were slightly more women with 37 women and 17 men participating.

\subsubsection{Results - Pragmatic and Hedonic characteristics}

Following the analysis methodology outlined by Burmester et al (2002), the results of the items for the pragmatic quality and those for the hedonic quality were placed on the $\mathrm{x}$-axis and $y$-axis respectively to generate a portfolio of the ORIGIN HEMS (Figure 7). Using a confidence interval of $95 \%$, the pragmatic quality dimension, was found to lie within the neutral category and the hedonistic quality dimension between the neutral category and the self-oriented category. Since the ORIGIN HEMS interface lies predominantly within the neutral "character area" it is still rated as average. This means both qualities can be improved, the pragmatic quality more than the hedonic quality. The ORIGIN HEMS does not 
fully support the user in their tasks and could be made more pragmatic and simple to use. With respect to hedonic quality, the user is able to identify with the ORIGIN HEMS but further development could foster increased user attachment.

Figure 7 goes about here

\subsubsection{Results - Attractiveness of ORIGIN HEMS}

The next analysis step assessed the mean values of the grouped responses to provide a quantification of the product characteristics with each being measured using seven items within the AttrakDiff model. Hedonic quality is disaggregated into stimulation (HQS) and identity (HQI) and an overall assessment of the attractiveness (ATT) is derived (Figure 8).

Similar to the analysis discussed previously, the ORIGIN HEMS was rated between neutral and positive by its users. ATT is the attribute with the highest mean value implying that the design intent of the participatory group has to a significant extent been carried out. The lowest mean value can be observed on its pragmatic quality implying that users are relatively indifferent as to the usability of the product. The other two aspects of the hedonic quality are slightly better rated by the users, with the HQS (stimulation) rating slightly higher. Overall, it can be surmised that the ORIGIN HEMS is perceived as attractive by its users with interesting and stimulating content. It can be improved in all aspects but predominantly with respect to usability particular in its orientation towards fulfilment of tasks.

Figure 8 goes about here

\section{Impact of ORIGIN HEMS on community energy practices}

The ORIGIN project created and deployed end to end operation of a new breed of energy control architecture to facilitate demand response in a bespoke form in each of the validation communities. The architecture permitted the deployment of a range of different demand response programs that included optimal control of electrical storage, electric vehicles and electric space heating systems and the use of novel tariff systems linked to availability of renewable generation surplus. The ORIGIN HEMS was created as a part of this overall architecture and was viewed as a critical element in securing user participation in these actuated and incentivized demand response programs. It will also have had additional 
impact on changing user energy practice as a consequence of the community contextualized information. It is therefore difficult to quantify the changes in energy practice that can directly be assigned to the ORIGIN HEMS but the usage statistics underlie its importance in raising awareness. As an example of the impact made by the ORIGIN system, the basket of demand response actions led to increased consumption of locally generated renewable energy by $33 \%$ in the Tamera community and $16 \%$ in the Findhorn community (ORIGIN, 2016).

\section{DISCUSSION \& CONCLUSIONS}

The approach taken here cast a lead user group as the experts with responsibility for providing innovative design input for a novel home energy management system. This system was designed to communicate to participants when a surplus of locally generated renewable electricity was forecasted and then feedback how much of this surplus generation the participants used. The design output created by the lead user group during the participatory workshops created an array of communication methods that were not found in the prior art. A greater emphasis was placed on contextualising the information contained in energy feedback such that it was relevant to the user and/or community group. In this manner, visual imagery was found to be more popular than data rich displays, the latter more common in conventional, market available HEM systems. Whilst the time span of assessment used here is only marginally longer than the more typical four month period used in many previous studies, taken overall, the usage statistics for the designed system were highly encouraging. The co-designed interface, and the method of its implementation within these distinctive communities, seemed to secure sustained engagement over the period of assessment.

The assessment vehicle used to determine the attractiveness of the ORIGIN HEMS revealed the complexity of energy system user interface design. If the design focuses solely on usability, it may be perceived as "boring" by the users whereas if the hedonistic quality is improved to make it innovative and creative, the user may get overstrained. The output from the assessment vehicle indicated that the attractiveness of the product could still be improved. It was interesting that a significant aspect of the critical feedback identified by the assessment stemmed from participants desiring additional functionality; namely for finding task-related information for load-shifting behaviours. This perhaps highlights the way in which Björgvinsson et al (2010) describe how a designed object undergoes a transition to a designed thing once it is delivered to its participants. At this point, it becomes a matter of concern for them and in their deliberations they see further possibilities of interaction not 
envisaged during the initial participatory design phase. This hints at the need for a departure from a view of design as a discrete process to one which is a continuum. Further participatory design iterations would, for instance allow the ORIGIN HEMS to be modified to incorporate this task orientated functionality.

This paper has sought to capture some of the user-centred design innovations that have taken place within the ORIGIN project. This work has granted a unique opportunity to work with eco-communities as lead-users, and employ participatory design approaches to develop home energy management interfaces that yielded sustained and positive interactions by users. Beginning with the user has enabled radically different types of interface to be codesigned and their effectiveness established.

The principal objective of this paper was to envisage and deploy a novel, human centred innovation process for communicating energy related issues such that they contained meaning and relevance for a candidate community. This was stimulated by the evident flaws that exist with existing methods based on their highly inconsistent performance in field trials. The use of eco-communities to pilot this innovative design methodology does not in itself restrict its generalisation. Its basis was founded on well grounded, peer-reviewed research into participatory design. What is likely is that the design output will vary dependant on the makeup of the community to which it is applied and the objective functions they are seeking to address.

The process, by its very nature is time-consuming, particularly aspects of design anthropology and its use to produce numerous bespoke interfaces on a community by community basis is not practicable. However, the advent of mass customisation tools and methods for rapid development of personalised software offers a route by which core elements of the methodology proposed here could be generalised. For instance, a library of design artefacts could be created using a variety of different communities and subsequently used to create customised HEMS based on less invasive participatory approaches.

What is clear, even at this early stage of development, is that user-centred design appears to offer a way of creating 'communications about energy' that is meaningful, promoting response among participants. The achievement of this end goal is crucially important if the concept of an active energy citizen that accompanies much smart energy system thinking is to become more than an empty metaphor. Whilst there is still much work to be undertaken in further refining the developed interfaces and testing the final design's energy saving performance, the participatory design approach described in this paper represents a bold step in that direction. 


\section{ACKNOWLEDGMENTS}

The authors wish to acknowledge the assistance of the Findhorn College, Damanhur Federation and Tamera Healing Biotope I for their support of this research investigation. The research leading to these results has received funding from the European Union Seventh Framework Programme (FP7/2007-2013) under grant agreement № 314742. 


\section{REFERENCES}

Ambient Devices, (2015), http://www.ambientdevices.com/about/energy-devices, accessed April 2015

Anderson W., \& White V., (2009), Exploring consumer preferences for home energy display functionality, Centre for Sustainable Energy, Tech. Rep

Björgvinsson E., Ehn P., \& Hillgren P. A., (2010), Participatory design and democratizing innovation, In Proceedings of the 11th Biennial Participatory Design Conference, (41-50), ACM

Blevis E., (2007), Sustainable interaction design: invention \& disposal, renewal \& reuse, In Proceedings of the SIGCHI conference on Human factors in computing systems, (pp. 503512), ACM

Burchell K., Rettie R. \& Roberts T., (2014), Working together to save energy?, Report of the Smart Communities project

Burmester, M., Hassenzahl, M., \& Koller, F. (2002). Usability ist nicht alles-Wege zu attraktiven Produkten (Beyond Usability-Appeal of interactive Products). I-Com, 1(1_2002), $32-40$.

Buur J. \& Matthews B., (2008), Participatory innovation, International Journal of Innovation Management, 12(03), 255-273

Carroll J. M. \& Rosson M. B., (2007), Participatory design in community informatics, Design Studies, 28(3), 243-261

Darby S., (2006), The effectiveness of feedback on energy consumption, A Review for DEFRA of the Literature on Metering, Billing and direct Displays, 486,

DECC, (2014), UK National Energy Efficiency Action Plan, Department of Energy and Climate Change, UK Government

DECC, (2015a), Annual Statement of Emissions for 2013, Dept of Energy \& Climate Change, UK

DECC, (2015b), Regional variation of payment method for standard electricity (QEP 2.4.2), Department of Energy and Climate Change, UK Government

DiSalvo C., Nourbakhsh I., Holstiu, D., Aki, A. \& Louw M., (2008), The Neighbourhood Networks project: a case study of critical engagement and creative expression through 
participatory design, In Proceedings of the Tenth Anniversary Conference on Participatory Design, (41-50), Indiana University

Ehn P., (2008), Participation in design things, In Proceedings of the Tenth Anniversary

Conference on Participatory Design, (pp. 92-101), Indiana University

Ehrhardt-Martinez K., Donnelly K. A. \& Laitner S. (2010), Advanced metering initiatives and residential feedback programs: a meta-review for household electricity-saving opportunities, Washington, DC: American Council for an Energy-Efficient Economy

European Commission, (2014), Benchmarking smart metering deployment in the EU-27 with a focus on electricity, $\operatorname{SWD}(2014)$

EU (2011), A Roadmap for moving to a competitive low carbon economy in 2050, COM/2011/0112 final

Faruqui A., Sergici S. \& Sharif A. (2010), The impact of informational feedback on energy consumption - A survey of the experimental evidence, Energy, 35(4), 1598-1608

Foxon T. J., (2013), Transition pathways for a UK low carbon electricity future, Energy Policy, 52, 10-24

Gilman R., (1991), The eco-village challenge, Context, 29 (10)

Gram-Hanssen K., (2008), Consuming technologies - developing routines, Journal of Cleaner Production, 16: 1181-9

Hanington B. \& Martin B., (2012), Universal Methods of Design: 100 Ways to Research Complex Problems, Develop Innovative Ideas and Design Effective Solutions, Rockport Publishers

Hargreaves T., Nye M. \& Burgess J. (2010), Making energy visible: A qualitative field study of how householders interact with feedback from smart energy monitors, Energy Policy, 38(10), 6111-6119

Hassenzahl, M., Burmester, M. \& Koller, F. (2008), Der User Experience (UX) auf der Spur: Zum Einsatz von www.attrakdiff.de, In: Brau, H., Diefenbach, S., Hassenzahl, M., Koller, F., Peissner, M. \& Röse, K. (Hrsg.): Usability Professionals 2008, S. 78-82. Stuttgart: German Chapter der Usability Professionals Association.

IDEO, (2011), Human-Centered Design Toolkit: An Open-Source Toolkit to Inspire New Solutions in the Developing World

Kahneman, D. (2011). Thinking, fast and slow. London: Penguin. 
Karjalainen S., (2011), Consumer preferences for feedback on household electricity consumption, Energy and Buildings, 43(2), 458-467

Luck R., (2014), Learning How to Use Buildings: An Exploration of the Potential of Design Interactions to Support Transition to Low-Impact Community Living, Buildings, 4(4), 963-977

Muller M.J., (2003), Participatory design: the third space in $\mathrm{HCl}$, Human-computer interaction: Development process, 4235

Origin, (2015), http://www.origin-concept.eul, accessed January 2015

ORIGIN (2016), Orchestration of Renewable Integrated Generation in Neighbourhoods, EUFP7 Grant agreement number 314742, Final Report

Pruitt J., \& Adlin T. (2010), The persona lifecycle: keeping people in mind throughout product design. Morgan Kaufmann

Røpke I., (2009), Theories of practice-New inspiration for ecological economic studies on consumption, Ecological Economics, 68(10), 2490-2497

Shove E. \& Walker G., (2007), CAUTION! Transitions ahead: politics, practice, and sustainable transition management, Environment and Planning A, 39(4), 763-770

Stern N., (2007), Stern Review: The Economics of Climate Change, Cambridge University Press, Cambridge

Strengers Y., (2011), Negotiating everyday life: The role of energy and water consumption feedback, Journal of Consumer Culture, 11(3), 319-338

Tognazzini B., (1995), Tog on Software Design, Addison-Wesley Educational Publishers Inc, 1995

Van Dam S. S., Bakker C. A. \& Van Hal J. D. M., (2010), Home energy monitors: impact over the medium-term, Building Research \& Information, 38(5), 458-469

Walker, G.H., Taylor, A., Whittet, C., Lynn, C., Docherty, C., Owens, E. \& Galloway, S. (Under Review). A practical review of energy saving technology for ageing populations. Applied Ergonomics

Wilhite H., (2014), Insights from social practice and social learning theory for sustainable energy consumption, Flux 2/2014 (No 96), p. 24-30

Wilhite H., (2007), Will Efficient Technologies Save the World? A Call for New Thinking on the Ways that End-use Technologies Affect Energy Using Practices, Proceeding from the 
ECEEE 2007 Summer Study: Saving Energy — Just Do It, European Council for an EnergyEfficient Economy (2007), pp. 23-30 